\title{
Software Piracy among Technology Education Students: Investigating Property Rights in a Culture of Innovation
}

\author{
George Teston
}

When asked about individual perceptions of "technology," $68 \%$ of Americans primarily equate the term to the computer (International Technology Education Association, 2004). Although this perception under represents the true breadth of the field, the statistic does speak to the ubiquitous role the computer plays across many technology disciplines. Software has become the building block of all major industries and arguably, our modern civilization. Software drives the automation of manufacturing, medical research, avionics, telecommunications, engineering, and even our national defense. With software tools at the heart of design, problem-solving, and innovation for many major technology industries, technology education has accepted the essential role of software.

The International Technology Education Association (ITEA) (2005, p. 25), which supports a broad range of technology disciplines, asserts that students should learn how to apply principles of computer science as early as middle school. Computer science is among the disciplines the ITEA identifies for postsecondary study and technology careers (p.27). Two of the nationallyrecognized ITEA Standards for Technological Literacy content standards (eleven and twelve) are supported by the design and problem-solving skills involved in computer programming (ITEA, 2000). In light of this commitment, has the technology education classroom kept pace with the ethical challenges presented by ever-expanding computer contexts?

In recent years, the academic and popular literature has resounded with alarming software piracy statistics (see Al-Rafee \& Cronan, 2006; Batson, 2007; IDC, 2007; Kruger, 2004). According to The Economist (Gottlieb, 2007) and the Wall Street Journal (Batson, 2007), illegal pirated copies of commercial software represented a loss of $\$ 39.6$ billion in 2006. IDC Research (2007) estimates the loss to mount to $\$ 300$ billion over the next four years. The Business Software

George Teston is a former Associate Graduate Professor of Computer Information Systems and Educational Technology and currently serves as a Professor of Computer Management.. 
Alliance (2006) reports a global piracy rate of $35 \%$, that one in three commercial software installations circumvents purchase. Of the 230 million PC's shipped last year, only seven cents were spent on legitimate software for every dollar spent on hardware. The problem is also recognized by experts beyond industry (Forrester Research, 2005; Pew Internet Foundation, 2007) and by Congress, which formed the 2007 Congressional AntiPiracy Caucus in response to the crisis.

Regardless of the corporate sector's ability to absorb this loss or advocacy groups' cry for free software, piracy robs companies and programmers of their property rights and reduces future jobs for today's technology students. Like engineers, graphic designers, and other members of the technology community, programmers are paid for their creative skills in design and problem-solving. Without revenue for their creative products, the innovation cycle is seriously diminished.

The products of computer programming, and therefore the impact of piracy, touch many other technology fields, including: computer aided design, robotics, informatics, desktop publishing, and artificial intelligence. Yet unlike these fields, the public's interaction with computer software begins at a much, much earlier age. Does this early interaction with software facilitate greater maturity in software property values? Or does the early interaction precede the appropriate developmental window at which property values are formed? As our economic dependence on software continues to grow, the field of education technology must strive to produce future technology professionals who exhibit both facility and ethics with software.

This study sought to investigate the attitudes related to software piracy among a sample first encountering the developmental issues of software, students in three middle school technology education programs that include computer programming. The present study also provided comparison to an earlier study (Teston, 2002) to assess changes in piracy attitudes.

\section{Background and Purpose}

Because today's young technology education students represent tomorrow's innovators, their ethical development related to intellectual property is of particular concern. Hopper (2000) stated that almost half (48\%) of elementary and middle school students believe software piracy is legal. Kruger (2004) reported $40 \%$ of adult educators defend piracy within schools. Not surprisingly, student beliefs mirror those modeled by their teachers, with many young people (88\%) justifying piracy from a perception that individual software costs only pennies to produce and represents no harm (Kruger, 2004). Since preventive measures and legal deterrents do not seem effective in the face of increasing losses (Al-Rafee, 2006), it is important that we examine the attitudinal variables underlying the piracy phenomenon.

Kohlberg (1989) and Piaget (1965) observed that children acquire property morals through social interaction with tangible objects, whereby they experience 
loss and empathy. Kohlberg's seminal research in moral judgment provides a framework to predict moral attitudes and behavior. Kohlberg asserts that individuals learn to reconcile ethical decisions according to three progressive levels of moral reasoning: pre-conventional (avoiding punishment), conventional (abiding by law), and post-conventional (principled standards even in the absence of law). Kohlberg's research, which originally focused on fifth through seventh grade students in conflicting moral dilemma discussions, identified adolescence as the critical moral developmental period.

To streamline Kohlberg's methodology, James Rest developed the Defining Issues Test (1986), on which respondents evaluate ethical dilemmas to generate a scaled moral index score. D.I.T. validity and reliability was strongly reaffirmed in 1999 when Rest examined over 400 independently published DITbased articles (Al-Rafee, 2006).

While taking tangible property creates deprivation and represents a conspicuous act with clear opposing moral norms, pirating software usually does not deprive the owner of property and is far less obvious. Consider the graphic designer pirating photographs, the budding engineer pirating AutoCad, or the robotics student who discovers the ease of simply copying another student's time-intensive programming files. How well, if at all, are these abstractions and ambiguities discussed in the typical technology education class? Technology students may be unprepared to stretch the physical property experiences Kohlberg (1989) described to fit these digital contexts.

While much research, both classical and contemporary, addresses value development from the early adolescent perspective (Kohlberg, 1989; Piaget, 1965; Rest, 1979), little attention has been paid to computer ethics during these formative years. Friedman (1997) studied the motivations for piracy among late adolescents. Teston (2002) and Daniel (2002) extended this research to early adolescents, but no significant body of piracy research exists from the middle school technology education context.

The purpose of this study was to compare the attitudes, reasoning, and behavior in two groups: early adolescent technology students who view software piracy as ethical, and early adolescent technology students who view computer-based piracy as unethical. These groups were also compared to nontechnology middle school students from an earlier study of similar design (Teston, 2002). Students were asked to evaluate statements designed to measure their attitudes toward the ownership of tangible, prototypic property and intangible computer-based property, specifically software. Technology students were also asked about the property rights of other products of technology creativity: blueprints and brochures.

The objectives of this study were to:

1. Determine any difference in value orientation toward traditional, tangible property, and value orientation toward intangible computerbased property among early adolescent technology education students. 
2. Determine any difference in the moral reasoning levels of early adolescent technology education students who view software piracy as ethical and those who view software piracy as unethical.

3. Determine if moral orientation toward software piracy is related to actual general ethical behavior among early adolescent technology education students.

4. Determine if adolescent technology education students' perceptions of software ownership are related to their moral orientation toward software piracy.

5. Determine if there is a difference in software piracy attitudes among students in a technology education exploratory class compared to middle school students who have not had a technology education exploratory class.

\section{Population and Sample}

\section{Methodology}

The population for this study consisted of approximately 640 seventh-grade students from three suburban middle schools. Using technology education class periods as the unit of partition, groups of students were randomly selected, yielding an initial sample of 274 . After 23 surveys were disqualified for incomplete or improper responses, the remaining 251 surveys comprised the first phase of analysis, which included a statistical validity check to test for random or meaningless response patterns from the technology students. An analysis of response patterns revealed 14 surveys that were invalid according to the criterion of $50 \%$ or greater inconsistency between forced-choice items and counterpart Likert-scaled questions. The statistical analysis, results, and conclusions of this study are based on the remaining 237 valid subjects.

\section{Instrument and Data Collection}

A survey instrument was developed and field tested in a pilot study $(n=47)$ that preceded the formal study. The first two sections are based on Rest's (1979) Defining Issues Test, which consists of various dilemma stories to measure values, and has a test-retest reliability range of $70-85 \%$. The D.I.T. has been used extensively in piracy contexts and shown to correlate $(r>70 \mathrm{~s})$ to Kohlberg's interview methods (Al-Rafee, 2006; Logsdon, et. al., 1994; Wagner, 2001). The next section drew upon the survey content of Friedman (1997), with a prior reliability $>84.6 \%$. The last two sections contained new items on actual property knowledge and behaviors. The test-retest method indicated reliability $>$ $90 \%$ between two pilot rounds.

Section A of the survey presents a dilemma in which a girl considers whether to steal a drug for her sick mother. In section B, a boy considers whether to copy a computer game for a friend. Each story is followed by a multiple-choice question that asks how the character should act. Respondents are given a list of 16 justification statements (see Table 1) related to the dilemma and must rate each on a 5-point scale, where 4 indicates greatest 
importance and 0 indicates none. Sixteen justification statements measure value judgments such as, "Software is too expensive" and "Copying the CD will not harm anyone." Finally, respondents are asked to select the four most important justification issues and rank them. These four issues are then used to produce eight scores that indicate a level of moral development. A series of complexsounding, yet meaningless items yields two scores that measure consistency, random responses, and subjects "faking good."

Table 1

Students were asked to rate 16 affirmative and negative statements across 8 justification schemes for relative importance to his/her piracy decision.

\begin{tabular}{ll}
\hline Justification & Sample statement, +affirmative, -negative \\
\hline Actor's welfare & Bryan would still have the CD even if he copied it + \\
Other's welfare & Copying the CD prevents its makers from getting paid - \\
Other's welfare not affected & Software companies/programmers make money anyway + \\
Fairness and rights & Software is too expensive + \\
Social convention & Lots of people copy software to keep from paying for it + \\
Authority & If there is a law against it, he should not copy it - \\
Individual issue & Copying software just isn't an important issue - \\
Meaningless & Bryan uses a Blu-Ray Drive to copy disks. \\
\hline
\end{tabular}

Sections C and D consist of 14 dichotomous evaluation items. Section C is framed by moral orientation and asks respondents whether it is "OK" to perform various acts relating to tangible and intangible property, such as copying a $\mathrm{CD}$ for a friend and copying a protected photograph for a brochure assignment. Section D tests respondents' knowledge of copyright and property-ownership issues. Section E, asks respondents whether they have engaged in various acts of tangible and intangible nature including game pirating, multiple loading, and shoplifting.

\section{Analysis}

The first research questions were analyzed using descriptive statistics. The items for traditional property and software (steal, don't steal, indifferent) were analyzed using Chi-square analysis. Descriptive statistics and an independent $t$ test were used to analyze sample mean deviation between the groups for the thirty-two Likert justification scales. Forced choice items were analyzed using frequency distributions and cumulative frequencies. Weighted frequency scores were calculated by using degree of importance ( 0 to 4 ) as a multiplier. Finally, these scores were standardized by the number of subjects in each group. Data for the propiracy and antipiracy groups related to specific piracy contexts (self, other, and profit) were placed into bivariate tables and analyzed using McNemar's Test. To assess possible relationships between moral orientation and actual behavior, the Pearson product correlation test was used. The variable of perceived ownership was analyzed using basic descriptive statistics. 


\section{Findings}

Value comparisons for traditional property and computer-based property

The dilemma evaluations allowed for comparison of traditional, prototypic property orientation and computer-based property orientation. Subjects who indicated indifference were not analyzed $(n=57,24 \%)$. For the initial dilemma regarding the drug, $32.0 \%$ of subjects supported stealing it, while $43.8 \%$ did not. When posed with the dilemma of the software, $52.3 \%$ of subjects supported copying the $\mathrm{CD}$, compared to $32.0 \%$ who did not. Moral orientation to traditional property was also measured by subjects' evaluation of a bike theft dilemma. Overall, 9.7\% approved of stealing the bike. By contrast, 52.3\% approved of pirating for self and $63.4 \%$ endorsed pirating software from the Internet. When bike theft orientation was compared to software piracy orientation, the difference between groups was significant $\left(\mathrm{X}^{2}=116.42, \mathrm{P}-\right.$ value $=.0000$ ) in favor of piracy. These differences indicate greater moral adherence among middle school technology education students to notions of ownership regarding physical property than to software. This finding corresponds to earlier research (Al-Rafee \& Cronan, 2006; Daniel, 2002; Friedman, 1997; Teston, 2002) in which similar differences of moral orientation were found among late adolescents and adults.

Moral reasoning levels across pro-piracy and anti-piracy groups

Based on responses to sections A and B of the survey, subjects were classified into propiracy or antipiracy groups. Sixteen Likert-scale items followed each dilemma to assess respondents' justifications. An independent $\underline{t}$ test was used to assess sample mean deviation between the groups for the 32 Likert scales of the eight justification categories. Respondents also answered forced choice items rating the significance of their justifications, where 4 indicated greatest importance. Results were compiled by justification categories and standardized by the number of subjects in each group: antipiracy $(n=76)$ and propiracy $(n=124)$.

Results indicated logical consistency between the drug and software contexts for both groups. Independent t tests for sample mean deviation of the Likert justification scores between groups revealed no significant differences $(p$ $<.05)$ for the moral justification items related to traditional property. However, the moral reasoning of propiracy and antipiracy groups was quite different regarding software. Independent $t$-tests performed on the Likert scores indicated four significant justification categories for Propiracy students and three for Antipiracy Students.

In addition to the Likert justification items, analysis was performed on the forced-choice questions to measure respondents' reasoning. Frequency distributions for all items were calculated based on each respondent's rating of four items he or she deemed most important in evaluating the dilemma. Weighted scores were created using a factor of 4 for most important, down to zero for no importance. To allow for comparisons across variables, scores were combined into justification categories and then standardized. For the drug 
dilemma, both propiracy and antipiracy subjects exhibited similar reasoning (greatest to least): actor's welfare, other's welfare, authority, fairness and rights, social convention, and individual issue.

\section{Table 2}

Significantly rated justifications (where Likert value 4 indicates greatest)

\begin{tabular}{|c|c|c|c|}
\hline Propiracy Students & Mean & Antipiracy Students & Mean \\
\hline $\begin{array}{l}\text { Social Convention } \\
\text { "everyone does it" }\end{array}$ & 2.98 & $\begin{array}{l}\text { Authority } \\
\text { "law against it" }\end{array}$ & 3.61 \\
\hline $\begin{array}{l}\text { Individual Issue } \\
\text { "not important" }\end{array}$ & 2.90 & $\begin{array}{l}\text { Fairness and rights } \\
\text { "no right to copy" }\end{array}$ & 3.29 \\
\hline $\begin{array}{l}\text { Actor's welfare } \\
\text { "self-interest to pirate" }\end{array}$ & 2.71 & $\begin{array}{l}\text { Other's Welfare } \\
\text { "deprives compensation" }\end{array}$ & 2.94 \\
\hline $\begin{array}{l}\text { Other's welfare not affected } \\
\text { "no one harmed in piracy" }\end{array}$ & 2.69 & & \\
\hline
\end{tabular}

Table 3

Forced-Choice Piracy Justification Scores Standardized Across Groups

\begin{tabular}{|c|c|c|c|c|}
\hline \multirow[b]{2}{*}{ Moral justification } & \multicolumn{2}{|c|}{ Propiracy $(n=124)$} & \multicolumn{2}{|c|}{ Antipiracy $(n=76)$} \\
\hline & $\begin{array}{l}\text { Traditional } \\
\text { Property }\end{array}$ & Software & $\begin{array}{l}\text { Traditional } \\
\text { Property }\end{array}$ & Software \\
\hline Actor's welfare & 3.17 & 1.20 & 3.01 & 1.78 \\
\hline Other's welfare & 1.69 & 1.47 & 1.90 & 1.52 \\
\hline Authority & 1.37 & 1.45 & 1.40 & 2.79 \\
\hline Fairness \& rights & 1.14 & 1.55 & 1.42 & 1.90 \\
\hline Other's welfare not affected & 1.04 & 1.29 & 1.19 & 0.17 \\
\hline Social convention & 0.92 & 0.96 & 0.78 & 0.73 \\
\hline Individual issue & 0.50 & 1.84 & 0.30 & 0.97 \\
\hline Meaningless & 0.17 & 0.24 & 0.01 & 0.14 \\
\hline
\end{tabular}

Note: Weighted scores obtained from two survey items each, then standardized across groups.

The forced-choice analysis revealed reasoning differences between groups regarding software. First, both groups demonstrated dominant "actor's welfare" reasoning for traditional property and a dramatic decline of the same reasoning for the software piracy. Second, the antipiracy group exhibited a $99.2 \%$ increase in "authority" reasoning preference for the software scenario, almost twice that of the traditional property scenario. Third, both groups showed significantly higher scores in the software scenario for the "individual issue" category. This indicates a higher preference among propiracy students for social convention in software piracy contexts. Lastly, and perhaps most interesting, the "other's welfare not affected" justification was markedly different between groups for the software context, clearly indicating a lack of empathy among the propiracy students for the programmers and companies. This lack of apparent empathy is notable given that these students have all received computer programming experiences in their technology education courses. 
Moral orientation toward software piracy and actual general ethical behavior

Eleven yes/no items measured students' general and piracy-related behaviors. With regard to the entire sample, $27.4 \%$ reported having shoplifted, while $72.6 \%$ denied such acts. The variable for self-reported shoplifting was not significant across propiracy and antipiracy groups. While only $9.7 \%$ advocated taking the bike, $69.2 \%$ supported copying unauthorized photographs for a brochure design and 58.6\% supported copying a former student's CAD files. In terms of actual behaviors, $61.6 \%$ of technology students responded that they had actually used another person's CDs for installation of software on their computer and $68.3 \%$ indicated that they had copied software CDs for someone else. Of those subjects, $89.3 \%$ indicated an otherwise moral orientation by responding that they did not approve of taking the bike. While $52.3 \%$ of the sample advocated piracy for the person in the survey scenario, far more $(68.3 \%)$ reported self piracy behaviors - indicating that $16 \%$ pirate even though they do not advocate the act.

Perceptions of software ownership and attitudes toward software piracy

Of the propiracy students, $54.0 \%$ indicated that software is public property, compared to $53.9 \%$ of the antipiracy students. Pearson correlation analysis results $(r=.0043)$ indicated no linear relationship between perceived software property rights and piracy attitudes. Remarkably, over half of students, regardless of piracy orientation, believe that software is public property.

Another item measured ambiguity of software ownership. Without distinction of piracy orientation, $60.3 \%$ of respondents indicated that the manufacturer does not retain any property rights to software following consumer purchase. The largest relative response group was clearly the propiracy students who rejected the manufacturer's retention of property rights. Pearson correlation results $(r=-.19, p=.0092)$ confirmed a modest inverse correlation between piracy orientation and supportive attitudes about authors' retention of property rights. This appears to highlight an instructional need regarding intellectual property rights.

\section{The technology education variable in software piracy attitudes}

The final objective of this investigation was to determine if middle school technology education students who have had computer programming exploration would have different attitudes from those measured by Teston (2002) among a general middle school population. The researcher hypothesized that the exposure to programming and design of software solutions in the technology education curriculum would make a positive difference by providing students (a) empathy to the programmer's creative efforts, (b) experience with intellectual property, (c) cursory knowledge of copyright/patent law, and (d) better understanding of the economic impact. Surprisingly, the attitudes of the technology education exploratory group were not significantly different from those measured originally in a general middle school population. In fact, the results were quite congruent. Teston's 2002 study found 51.9\% in favor of 
piracy acts and the present study found $52.3 \%$ in favor. Rather than finding more sophisticated moral reasoning related to software property rights, the group appears comparable to their non-technology peers. Yet the technology education students report significantly higher rates of actual piracy behaviors. General middle schoolers reported $45.8 \%$ for copied software CDs and $53.4 \%$ for pirated installations (Teston, 2002). In contrast, the technology education middle school students reported $68.3 \%$ for copied software and $61.6 \%$ for pirated installations, 22.5 and 8.2 increases respectively. Perhaps technology education students are simply higher consumers of software given their interests and exposure. Further research in this area would be valuable, as neither the 2002 study nor the present one sought to measure levels of software usage as a possible piracy variable.

\section{Implications for Technology Education}

Two of the ITEA STL Content Standards relate to the unique property rights issues highlighted by software piracy: the social and economic impact of technology (Standard 4) and the role of society in the development of technology (Standard 6). Some states have specifically articulated software property rights objectives in their implementation of the ITEA STL Standards (Alabama Learning Exchange, 2007). Additionally, seven mid-western states have addressed software property rights as part of the Mid-continent Research for Education and Learning Standards (2007), which states in Technology Standard 3 that, "Starting in grades 3-5, students will understand the concept of software piracy and that piracy is a violation of copyright laws." Regrettably, many states do not specifically include software property rights in their standards and even fewer appear to address this at the middle school level, a time when Kohlberg (1989) asserts ethics instruction has the greatest impact. This gap highlights significance for the present study and warrants additional efforts by the technology education community.

This study revealed a difference in moral orientation toward traditional, tangible property compared to intangible, computer-based property among early adolescents, but that this difference does not result from different moral reasoning levels between the propiracy and antipiracy students. Instead, the majority of students, $58.7 \%$ of the full sample and $62.7 \%$ of the propiracy students, had erroneous concepts of innovator's rights beyond the point of sale. This suggests curricular failure to address social convention, misconceptions of software ownership, and copyright laws.

The hallmarks of Kohlberg's (1989) conventional stage are the ability to take another person's perspective and adherence to rules for the sake of social order. Since the stage includes ages nine to twenty, young and late adolescents represent ideal groups to consider Kohlberg's theories in the digital property context. Friedman (1997) found the second most popular justification for pirating software among late adolescents was that it didn't harm anyone, empathetic yet inverted logic. In contrast to Friedman's sample of empathetic eleventh and twelfth graders, this sample of seventh graders presented dominant 
egocentric (propiracy) and authority-driven (antipiracy) reasoning. This clear difference in empathy supports Kohlberg's and Piaget's (1965) age-progressive reasoning levels. This also suggests that the development of general empathy may not translate to digital property contexts if the individual lacks concrete experience or understanding of intellectual property. Whether due to issues of social convention or perceptions of software that escape prototypic property experiences in childhood, computer software appears to present a unique moral paradigm.

Kohlberg (1989) and Piaget (1965) both asserted that recognition of ownership must precede observance of related property rights. Technology education efforts may therefore offer a positive impact by addressing fundamentals of intellectual property ownership. Not only programmers, but technology education students in all fields of innovation and design (engineering, biotech, information, construction, and manufacturing) should have their growth in skill balanced with growth in ethics.

Piracy behaviors among the present sample of middle school technology students was significantly greater than those reported in Teston's (2002) sample of middle school non-technology education students. In terms of frequency, other research suggests young people engage in piracy more often than older users (Pew, 2007; Wagner, 2001). The significant presence of this behavior at such a young age, coupled with majority misconceptions of property rights, highlights an important outcome for this study. If early adolescence is indeed the optimum period for moral education (Bloom, 1964; Kohlberg, 1989; Piaget, 1965), then piracy education and intervention efforts should be targeted more strategically at this population.

Roger Bybee (2003), a noted advocate for the new standards for technological literacy, asserted that technology involves synthesis of ideas from a variety of disciplines. The interdisciplinary nature of digital property concepts provides ripe opportunity for integration across the curriculum. Teachers can easily leverage the topic of intellectual property rights for connections in math (economics), social studies (copyright laws and cultural differences toward piracy), art (intellectual property types), science (the rights of inventors), and even language arts (plagiarism).

Federal law, which recently increased fines to $\$ 250,000$ and jail terms to 5 years, stridently reflects the pervasiveness of this problem in our society and the importance of protecting digital innovation (Software and Information Industry Association, 2007). Yet, the current classroom conversation on intellectual property rights appears largely silent. Students rate their teachers dead last for intellectual property instruction (18\%, compared to friends $30 \%$, and television $59 \%$ ), indicating that we are failing to meet this curricular need (Ishizuka, 2004). The technology education classroom, with its culture of design and innovation, is the prime context to address this disturbing gap.

A rich opportunity exists for collegiate technology education leaders to collaborate with grade-school teachers and technology education coordinators to encourage lesson plans and dialogue on intellectual property rights. The 57 
university-level technology teacher education programs in the United States also have much to offer this discussion (Warner \& Morford, 2004). Their students ultimately become the certified teachers, delivering technology education curricula (both cognitive and affective) in the public school arena.

Technology educators, at all levels, should be exposed to the welldocumented instructional methods for ethics education. Kohlberg (1989) provides specific successful strategies for ethics education, the core of which is carefully-led discussions about progressively complex, ethically-conflicting, property dilemmas. These activities in moral conflict and cognitive resolution can help technology education students to dialogue and develop values for a range of technology properties, from engineering designs to software. In support of this, technology education textbooks from middle school to graduate school should include a chapter on ethics - one that appears within the core of the text, not near the end where ethics content is generally relegated.

A number of strategies exist for the technology education community to effectuate positive change in digital property rights:

Pedagogy - integration of property rights issues into design and problemsolving instruction for immediate relevance and interdisciplinary connections

Curriculum - textbooks and resources that specifically address intellectual property rights across the breadth of technology disciplines

Professional Development - strategies to equip technology educators to lead moral dilemma discussions for authentic student change Research - continued inquiry into digital property attitudes, behaviors, and university connections for pre-service teachers

If we implement strategies to teach technology students to be ethically conscious of innovation and property rights, we will help address the piracy problem facing the software industry today and bolster property rights across all the various fields of technology design and innovation. The rapid rate of technological expansion does not have to exceed our society's rate of moral accommodation.

\section{References}

Al-Rafee, S. and Cronan, T. (2006). Digital piracy: factors that influence attitude toward behavior. Journal of Business Ethics, 63, 237-259.

Alabama Learning Exchange (2007). Technology standards, grades 6-8. Alabama Technology Education Standards. Retrieved February 6, 2007, from http://alex.state.al.us/standardAll.php? grade $=7 \&$ subject $=$ TC\&summary $=2$

Batson, A. Software piracy: New policies help lift legitimate market; Still a major problem. (2007, May 16). Wall Street Journal. Retrieved July 30, 2007, from http://online.wsj.com/article/SB117921917091203166.html 
Blatt, M. and Kohlberg, L. (1975). The effects of classroom moral discussion upon children's level of moral reasoning. Journal of Moral Education, 4 (2), 129-161.

Bloom, B. (1964). Stability and Change in Human Characteristics. New York: Wiley.

Business Software Alliance. (2006). Global piracy study. Retrieved February 12, 2008, from http://www.bsa.org/globalstudy

Bybee, R. (2003). Fulfilling a promise: Standards for technology literacy. The Technology Teacher, 62(6), 23-26.

Daniel, A. (2002). An exploration of middle and high school students' perceptions of deviant behavior when using computers and the Internet. Proceedings of the 2002 ASCUE Conference, June 9-13, 2002.

Forrester Research. (2005). Court Rules Against Grokster, Piracy Goes On. Retrieved February 6, 2007, from http://www.forrester.com/go?docid=37300

Friedman, B. (1997). Social judgments and technological innovation: Adolescents'understanding of property, privacy, and electronic information, Computers in Human Behavior, 13(3), 327-351.

Gottlieb, A. (Ed.) (May 29, 2007). Software piracy: Free loaders. Economist.com. Retrieved July 30, 2007, from http://www.economist.com/research/displaystory.cfm?story_id=9248524.

Gross, G (2008). Software piracy conviction sends two to jail. PCWorld, Retrieved March 8, 2008, from http://www.pcworld.com/article/id,143252pg, $1 /$ article.html

Hopper, D. (2000). Teaching virtual morality: FBI pushes for cyber ethics. ABC News.Retrieved January 28, 2007, from .

IDC white paper: the software piracy problem. (2007, June 19). BusinessWeek. Retrieved July 30, 2007, from http://whitepapers.businessweek.com/detail/RES/1182270741_939.html.

International Technology Education Association (2000). Standards for technology literacy: Content for the study of technology. Reston, VA.

International Technology Education Association (2004). The Second Installment of the ITEA/Gallup Poll and What It Reveals as to How Americans Think About Technology. Retrieved January 28, 2007, from http://www.iteaconnect.org/TAA/PDFs/GallupPoll2004.pdf

International Technology Education Association (2005). Technology for all Americans: A rationale and structure for the study of technology. Reston, VA.

Ishizuka, K. (2004). Kids: Stealing digital data ok. School Library Journal, $50(8), 18$.

Kohlberg, L. (1989). Lawrence Kohlberg's Approach to Moral Education. New York:Columbia University Press.

Kruger, B. (2004). Failing intellectual property protection 101. The Journal of Technological Horizons in Education,13(9), 48. 
Logsdon, J., Thompson, J., and Redi, R. (1994). Software piracy: Is it related to level of moral judgment? Journal of Business Ethics, 13, 849-857.

Mid-continent Research for Education and Learning (2007). Technology Standards. Retrieved January 28, 2007, from ttp://www.mcrel.org/compendium/reference.asp? item=benchmark\&BenchmarkID $=672 \&$ subjectID $=19$

Pew Internet Foundation. (2007) Pew Internet and American Life Project. Washington,D.C., Retrieved July 28, 2007, from http://www.pewinternet.org/reports.asp

Piaget, J. (1965). The Moral Judgment of the Child. New York: The Free Press.

Rest, J. (1979). Development in Judging Moral Issues. Minneapolis, MN: University of Minnesota Press.

Software and Information Industry Association. (2007) SIIA Anti-piracy 2006 Year in Review. Retrieved July 25, 2007, from http://www.siia.net/piracy/

Teston, G. (2002). A developmental perspective of computer and information technology ethics: Piracy of software and digital music by young adolescents. Dissertation Abstracts International: Section B: The Sciences \& Engineering, 62, 5815.

Wagner, S. (2001). Considerations in ethical decision-making and software piracy. Journal of Business Ethics, 29(1), 161-167.

Warner, S. and Morford, L. (2004). The status of design in technology teacher education in the United States. Journal of Technology Education, 15(2), 3345. 